Open Access

\title{
Absorptive and desorptive capacity of actors within university-industry relations: does technology transfer matter?
}

Davide Dell'Anno ${ }^{1 *}$ and Manlio del Giudice ${ }^{2}$

\author{
* Correspondence: davide. \\ dellanno@unina2.it \\ ${ }^{1}$ Department of Economics, Second \\ University of Naples, Capua, Italy \\ Full list of author information is \\ available at the end of the article
}

\begin{abstract}
Several management studies highlight the importance of collaborative relationships for university-industry knowledge and technology transfer. The present study examines the role of absorptive and desorptive capacity (A/DCAP) of actors in technology transfer processes by pointing out critical elements that may affect regional innovation systems. In this field of action, each university worldwide, as well as public and private research centers, interacts differently with industry. Cultural and economic variances make it difficult to outline one single global model governing knowledge and technology transfer. However, it is possible to identify elements and characteristics that might make this system efficient. Mere interaction is a necessary but not a sufficient condition to ensure that knowledge and technology flow through a feasible dyadic channel from university to industry (U-I) or vice versa (I-U). Indeed, the actors of the process have to develop organizational capabilities at all levels and units (i.e., individual and organizational) based on a social integration system which can facilitate their communication, thus helping to share activities. In this regard, we present a systematic review of research into academic involvement in the regional innovation development environment by identifying individual as well as organizational and institutional layers of this crossrelationship. Apart from being more widely applied, AVDCAP is strictly important for academics in order to access resources and results able to support their research agendas.
\end{abstract}

Keywords: Absorptive capacity, Desorptive capacity, Knowledge transfer, Technology transfer, Organizational culture, University-industry relation

\section{Background}

Since modern economies are based on knowledge, in order to survive, an organization has to innovate constantly. Since the world of knowledge is based on complex and dynamic systems deeply characterized by factors like culture, economy, society, policy, and finance, one model alone is unable to express accurately and totally all its peculiarities. Indeed, a distinguishing feature of the present era is local markets for knowledge, sub-systems of a global market of knowledge. Operators who have knowledge in excess with respect to the internal capacity enhancement, or whose mission is the exchange of knowledge (universities and training systems in general), give knowledge to those who need it and who have the ability to acquire and enhance it (Davenport and Prusak 2000). The key players of these systems are universities and industry, and it is important to note that exchanges between them take place in two-way directions, especially if informal. Metrics can evaluate the 
available data on formal collaborations that are in any case limited, especially in terms of public, official sources. As a consequence, the problem is that a significant share of collaborative activity remains unmeasured, not counted. During the past decade, several surveys, such as the CIS in Europe, the Association of University Technology Managers (AUTM) or Protom-Europe, PatVal-EU, have sought to analyze the commercialization of science, and others are available on major countries and/or industrial sectors.

According to analyses conducted elsewhere, firms treat internal resources and external collaboration partners as the most important sources of innovation (inside-out), followed by collaborations with other enterprises within the group, customers and clients, competitors, and, lastly, universities and PROs (Public Research Organizations) (outside-in).

Our research path starting from these assumptions has sought to identify variables able to affect the spread, and success, of such collaboration. Recently, such collaboration has been perceived as growing, becoming a critical component of an efficient national innovation system. Yet, in this context, in the world, there still coexist "North and South" systems.

With regard to collaboration with higher education or government research institutions, great country-by-country variation has been shown (OECD 2013, p. 127). The number of firms involved in collaborative activities for producing innovation is much higher in some countries (such as Finland) than in others, where it is very small (as in Mexico). Usually, large firms are two to three times more likely than small- and medium-sized enterprises to engage in such collaborations. However, it is very difficult to generalize these concepts because the size of enterprise is not the main discriminant for collaborative activities. This occurs especially if we consider differently the "business idiom" that comes from different capitalist cultures (i.e., collectivistic vs. individualistic ones) such as market structure and the knowledge environment, especially the evolution of the industry life cycle (Rothwell and Dodgson 1994; Rogers 2004). According to Rothwell and Dodgson (1994, p. 323) for instance, innovation is more relevant in small firms where entry costs are lower and niche markets already exist. Along an industry life cycle, the relationship between firm size and innovation is likely to evolve from a more favorable environment for small firms in the early stage to a mature situation where a higher concentration is found in both innovation and markets. In general, there are great differences across countries depending also on the type of collaboration but when we look at these surveys, the results are somewhat ambiguous.

That said, the academic literature is unanimous in emphasizing the importance of the strategic role played by academic research and hence by the interaction between academia and industry in facilitating social and economic development of nations (Mansfield 1991; David and Foray 1995; Freeman 1991; Lundvall 1992; Nelson 1993; Patel and Pavitt 1994; Feller 1990; Rothwell 1992; Rosenberg and Nelson 1994; Rothwell and Dodgson 1994; Branscomb et al. 1999; Etzkowitz and Leydesdorff 2000). Policymakers agree with this vision: cooperation and knowledge transfer initiatives involving universities have become a top priority for many countries, even if there are different ways of local applications (known as "European Paradox" EC 2002; OECD 2013).

Studies focusing on university technology transfer are based on system theories like the resource dependence theory (Pfeffer and Salancik 1978), institutional theory (Oliver 1991), agency theory (Arrow 1985; Eisenhard 1989), transaction cost theory (Williamson 1985), 
revenue theory of costs (Bowen 1980), and the resource-based approach (Barney 1991; Penrose 1959, 1995).

In the academic system, there are said to be two different worlds: science and the commercialization of science. The interactions between these two dimensions-of a unique system-are complex and hence not always systematic and "natural," thereby generating the so-called paradox of knowledge: the conviction of the importance of the knowledge is unanimous but it is not everywhere managed in a strategic manner. Universities have different attitudes to the problem of the distribution of the results of innovations developed in their laboratories, since exploitation of research results (performance and success) is influenced by several factors.

In this regard, this study focuses on the relationships of external and internal stimuli using a multifaceted framework based on university and industry features able to influence technology transfer processes. At its core, we place the absorptive and desorptive capacity (A/DCAP) of actors.

The concept of absorptive capacity (ACAP) originated in macroeconomics during the 1960s (Calkins R.D. in the foreword to Adler 1965). Since the seminal work of Cohen and Levinthal (1990) who adapted this macroeconomic concept to organizations, it has been investigated from many perspectives (Kedia and Bhagat 1988, p. 561). There are countless theoretical and empirical contributions that deal with this issue and focus on the connections between knowledge and innovation. Absorptive capacity is described as the ability of an organization to recognize the value of new, external information, assimilate it, and apply it to commercial ends (Cohen and Levinthal 1990) and as such facilitates knowledge accumulation and its subsequent use; it is considered a critical resource that depends on the organization's level of prior related knowledge and determines the organization's innovative capabilities.

Recently, the term "desorptive capacity" (DCAP) has appeared more frequently in current scientific discussions along with "absorptive capacity," both considered as cognitive barriers/facilitators to knowledge transfer (Le Masson et al. 2012). Absorptive and desorptive capacity both represent important components of a firm's ability to create new knowledge. According to the leading literature on the topic (Nonaka and Takeuchi 1995), knowledge is the result of the interaction between the actors (transferor and recipient). Hence, we can assert that it depends on the A/DCAP levels of both.

If organizations must have the competencies for understanding, decoding, and using ideas of others, it is fundamental that they should be able to transfer outward knowledge. Further, in the absence of this "right combination," the potential to innovate still appears to be very low and thus science-based collaborations are likely to be very rare.

The growth of opportunities for interaction between academia and industry reduces the trade-off between exploration and exploitation. This is necessary because the failure to balance the exploration of new knowledge and exploitation of existing knowledge generates two different conditions. Firstly, it implies that those who invest in exploration and do not care about exploitation will be likely to bear the costs without being able to benefit from them. Secondly, it means that those who focus on exploitation without participating in the creation of knowledge are likely to crystallize their work, missing opportunities.

The policy choices of national governments and supranational organizations guide research investments in scientific areas and sectors considered strategic. Consequently, 
government policies are essential to promote opportunities for economic actors by helping firms approach and collaborate with universities. In our opinion, the results depend only on the absorptive and desorptive capacity levels both of universities and industry. High uncertainty, high information asymmetries between actors, high transaction costs, high grade of probable spillovers (low level of appropriation), and different (divergent) time reference interests are all recurrent obstacles. As a consequence, in many countries, there are public promotion programs supporting collaborative research between industry and public science institutions (industry science links (ISL)) in order to remove such barriers.

\section{Methods}

The present study aims at exploring some theoretical implications of A/DCAP on technology transfer processes within university-industry relations. This specific context of investigation lends paper its originality vis-à-vis the existing literature. In order to achieve this purpose, after a preliminary section instrumentally used to depict the boundaries of our research field, we developed a conceptual discussion organized in four steps. Firstly, we explore and summarize the literature relevant to the research path; secondly, we focus on the main factors that influence the relationship between universities and industry, especially cultural factors. Thirdly, we frame a proposal based on the A/DCAP in order to interpret and optimize the process of technology transfer between universities and industry. Finally, we draw conclusions, identifying limitations and making suggestions for future research.

\section{Literature review}

This section provides an overview of topics discussed in the literature relevant to our research path, classified into three areas: (i) interactions between organizations, (ii) knowledge transfer, and (iii) absorptive and/or desorptive capacity.

\section{University and industry interactions}

It is well established by the literature that industry and university are culturally diverse and divergent. That said, they are-or should be-united by mutual interest that should lead them to collaborate to enhance the applications of scientific results within the business community. A typical researcher usually considers money as a means of scientific progress whereas the traditional businessperson believes that money is the end of the process and that science is the means. Communication between those two worlds could be made easier from shared research directions; if both conduct basic research, then industry and university are more likely to share a kind of common vocabulary.

Universities and firms are not direct competitors in output markets since their respective missions are different. Institutions offer new technical knowledge oriented toward developing new technologies and for products very new to the market. These collaboration activities take place in the early stages of the innovation process when there is high technological uncertainty and still low demand. Consequently, only a select set of firms within some industries, using specific technologies (e.g., bio- and nano-technology), have a strong interest in the expertise offered by universities.

The specific characteristics of scientific knowledge characterize the $R \& D$ cooperation between universities and industry. This type of collaboration presents high uncertainty, high information asymmetries between partners, high transaction costs for knowledge 
exchange requiring the presence of absorptive capacity, high spillovers to other market actors, and restrictions for financing knowledge production and exchange activities due to risk-averse and short-term oriented financial markets (Veugelers and Cassiman 2005; Del Giudice et al. 2013).

Furthermore, abandoning the previous belief that the generation of new knowledge is mostly an internal process, the boundaries between the organization's knowledge stock and external knowledge stock are nowadays considered blurred. In this context, knowledge is recognized as a strategic source, fundamental to create a competitive advantage ("valuable, rare, and inimitable," Teece 1988) for an organization. However, this goal is subject to verification of the ability to integrate it into its activities and presents limits and complexity to convert into performance improvement.

Bishop et al. (2011), from interactions with universities which may contribute to a firm's explorative and exploitative learning capabilities, acknowledge three broad types of benefits: (i) university research could improve the firm's understanding of the foundations of particular phenomena and enhance awareness of new research and technological opportunities; (ii) interactions with universities can also contribute to enhance the capacity of firms to exploit new or existing knowledge to create new products or processes or to achieve cost reductions in developing existing products or processes; and( iii) close interaction between universities and company personnel may enhance the problem-solving capabilities of firms, while recruitment of skilled graduates and training of firm personnel will increase the firm's capacity to interpret and transmit the knowledge acquired throughout the organization.

Research suggests (Schofield 2013) that in the field of collaboration between university and industry, there are three broad levels affecting potential success, namely internal, organizational, and individual processes and resources, partly controlled; environmental, related to market conditions and political, economic, and legal risks; and relational and cultural factors able to enhance or inhibit success.

Segarra-Blasco and Arauzo-Carod (2008) analyze a Spanish version of the Community Innovation Survey (CIS-3) to obtain data about the R\&D cooperation of 4150 innovative firms in Spain and maintain that a firm's size, $R \& D$ intensity, and absorptive capacity, as well as access to public subsidies, positively affect a firm's capacity to cooperate with universities. In their conclusion, they note that if public policies are not heavily R\&D-oriented, innovative firms suffer from a lack of support that is an important barrier to innovation. It is widely held that the role of universities in innovation systems is particularly important in countries specialized in low-technology industries. In accordance with the Quintuple Helix innovation model (Carayannis et al. 2012), the natural environments of society and the economy should also act as drivers for knowledge production and innovation. Therefore, they should define opportunities for the whole knowledge economy. The opportunities linked to knowledge and technology transfer between university and industry are embedded in cultural aspects that we recognize as the most important factors to influence it (Del Giudice et al. 2012).

\section{Knowledge transfer}

This happens when a unit that learns from the experience of another changes its knowledge base by integrating it, in order to engender a new configuration of its own competencies. It 
is more appropriate to point out that the transfer of knowledge can be defined by multiple points of view and it should be differentiated from the transfer of technology (technology transfer or commercialization of science). Szulanski (1996) describes knowledge transfer as a process of dyadic exchanges between the source and the recipient through four stages: initiation and implementation, including (i) events that lead to the decision to transfer from the source to the recipient and (ii) the flow of knowledge; and ramp-up and integration that begin when the recipient starts utilizing the transferred knowledge. The ability to exploit knowledge is precisely the "realized absorptive capacity" (Zahra and George 2002).

The non-rival nature of knowledge permits organizations to exploit it at the same time both internally and externally. This depends on the level of absorptive capacity that makes the external knowledge accessible and usable (Robertson et al. 2012). Success of R\&D knowledge transfer can be defined in many ways. Successful transfer is one that produces a satisfied recipient able to re-create product designs, manufacturing processes, and new organizational designs. In order to absorb knowledge, the recipient converts it, adapts it, or reconfigures it, in the firm's system formed by human assets, technical tools, and organizational routines. The perceived success also depends on the degree of ownership, commitment to, and satisfaction with the transferred knowledge.

Specifically in the process of knowledge transfer between academia and industry, given its strategic role in the national economic and social growth, we can identify push and pull factors fostered by asymmetries of information between multiple stakeholders each with different objectives. In this landscape, we count locally distinct drivers and barriers to a successful interaction following the logic of the triple helix model (Etzkowitz 1998; Etzkowitz and Leydesdorff et al. 2000).

\section{Absorptive and/or desorptive capacity}

In the managerial literature (Cohen and Levinthal 1990; Lane and Lubatkin 1998; Todorova and Durisin 2007), absorptive and desorptive capacity are generally used to refer to an organization. That said, in accordance with Paulsen and Hjertø (2010), it would be more correct to use the terms to refer to the sum of individuals/groups/divisions of A/ DCAP which is clearly positively related to group/division/individual knowledge transfer.

At the outset, it is appropriate to highlight the fact that absorptive capacity and the "capability to absorb" have two different meanings, especially for an organization formed by many operators. Absorptive capacity is a function of the knowledge that remains and that can be assimilated; the capability to absorb is linked to the structure and can increase. Absorptive capacity is the ability to find and recognize the potential value of new external information, assimilate it, and apply it to commercial ends. By contrast, desorptive capacity could be just considered the reverse, as the ability to release knowledge toward a recipient that is able to give it, immediately or in the near future, a commercial output. A/DCAP are both influenced by the degree of motivation-to transfer and/or learn and use-that actors belonging to both sides (university to industry (U-I)) attribute to the transfer process (Minbaeva et al. 2003). It is important that transferor and recipient perceive the importance of the transfer in order to have greater motivation to support it. Teaching/learning skills, a gap in the level of technical skills, personal experience, and purpose of the transfer are all relevant to the success of the transfer process. 
Volberda et al. (2010), through a bibliometric analysis based on 1213 publications from 1992 to 2005, mapped contributions, constructs, and implications of absorptive capacity in six major organizational theories: learning, innovation, managerial cognition, knowledge-based view of the firm, dynamic capabilities, and co-evolution. They concluded by developing an integrative framework of ACAP that identifies the underlying dimensions, its multi-level antecedents (managerial, intra-organizational, inter-organizational), its outcomes, and the contextual factors (environmental conditions, prior related knowledge) that affect ACAP.

Dine Rabeh (2013) proposes three referential definitions of absorptive capacity, two being single constructs (Cohen and Levinthal 1990; Lane et al. 2006) and one a double subset construct (Zahra and George 2002), and lists ten antecedents of absorptive capacity. The model proposed subdivides absorptive capacity into three main subsets: internal (based on social and technical), external (based on external relations), and financial. Social resources and capability include all the human, cultural, and procedural aspects that may influence the capacity of a company to acquire external knowledge, while technical absorptive capacity reflects the technical capabilities that may be employed for the same end (p. 16).

Absorptive capacity is considered by some authors (Lane and Lubatkin 1998; Zahra and George 2002; Carlsson 2005) a dynamic capability: a capability to renew an organization's competences, achieving congruence with changing environments, which is able to influence the firm's processes to build organizational capability using knowledge.

In a context of alliance partnership, Lane and Lubatkin (1998) proposed that the ability to learn is jointly determined by the relative characteristics of the student's and the teacher's organizations and that a student's absorptive capacity depends upon the specific type of new knowledge offered by the teacher, the similarity between the student's and teacher's organizations, and the student's familiarity with the teacher's set of organizational problems.

Lane et al. (2006) conducted a detailed analysis of 289 papers on absorptive capacity from 14 journals to assess how the construct had been utilized. Their reification of the construct led to define absorptive capacity as a firm's ability to utilize externally held knowledge, recognizing and understanding potentially valuable new knowledge outside the firm through exploratory learning, assimilating valuable new knowledge through transformative learning, and using the assimilated knowledge to create new knowledge and commercial outputs through exploitative learning (p. 856).

Flatten et al. (2011) develop and validate a four-factor measure of ACAP based on 14 items that assesses the degree to which a company engages in knowledge acquisition activities, assimilates acquired information into existing knowledge, transforms the newly adapted knowledge, and commercially exploits the transformed knowledge to its competitive advantage (p. 112).

We can conclude that ACAP and DCAP are two sides of the same coin and so they are mutually pull and push factors within technology transfer processes in a universityindustry relationship. Science-push absorptive capacity is based on scientific information from universities, non-profit research institutes, and firm's R\&D laboratories whereas demand-pull absorptive capacity is based on market information from customers, suppliers, competitors, conferences, and fairs (Murovec and Prodan 2009). The success of 
dialog on this topic depends on balancing push and pull factors and aligning reciprocal goals.

\section{Model proposal: factors influencing the university-industry knowledge transfer process}

We consider orientation-related barriers those factors that create differences in the orientations of industry and universities in the field of knowledge transfer; besides these, there are those that are related to conflicts over IP (Samuelson 1999)-transactionrelated barriers-not discussed here.

To provide an overview, we sought to represent graphically (Fig. 1) the critical factors that can determine the success or failure of the transfer of knowledge and technology between university and industry. Some of these will be elaborated below.

In the field of technology transfer between university and industry, we can highlight many critical elements, including geographical proximity and the information asymmetry. Collaborative partnerships with universities geographically nearby are useful in terms of "problem solving" especially for the transfer of tacit knowledge. The importance of

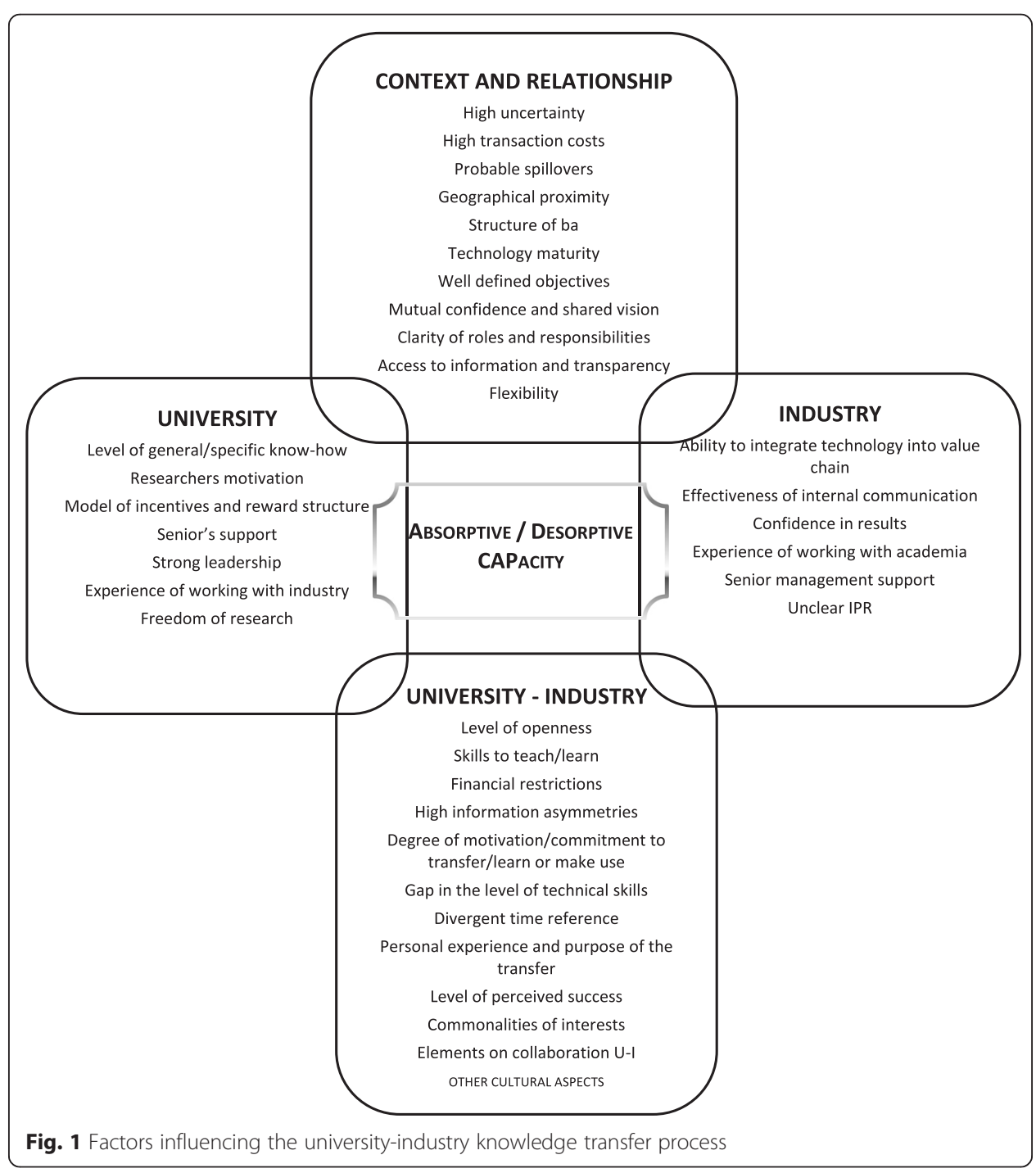


proximity between university and industry - or the original source of knowledge and the point of use-is still an open question, knowledge being intangible while tacit knowledge, with greater value added, is not easily codifiable. In the process of innovation, geographical proximity assumes a critical role when the type of technological knowledge is fed by multiple knowledge sources (universities, research laboratories, companies); this is equally true because the tacit nature, unobservable, complex, and systemic, blocks the use of scientific knowledge transfer tools and formalized means of communication (telecommunication networks, publications, license/sales know-how, reverse engineering). In these circumstances, just a face-to-face interaction makes it possible to feed and exchange the potential applications of knowledge; the process of knowledge creation therefore needs a place identified as $b a$ (Nonaka and Takeuchi 1995; Nonaka and Konno 1998), where there are participants and rules for participation and knowledge is shared, created, and used within collaborative relationships. Knowledge divorced from the $b a$ becomes information and as such can be notified individually as it is tangible, unlike the knowledge that is resident and intangible. The $b a$ feeds the spiral process and is not necessarily a physical place but has a specific space-time dimension that identifies it. Indeed, the $b a$ is a place where information is interpreted and assumes significance, validating Nietzsche's intuition that emphasizes the absence of facts, leaving the field to only interpretation. A feature of the $b a$, however, is that it is an open space, even if it requires-conceptually-borders, where participants can come and go, a context, therefore, in constant evolution.

As regards information asymmetry, there are many factors to consider. Cockburn and Henderson (1998) focused on two elements of collaboration between researchers working in different organizations: (i) co-authorship of papers and (ii) cross-citation.

The number of publications is considered an important indicator of research activity, especially of the investments in "doing basic science," even though it is not enough to share a publication to endorse the intellectual life of the wider scientific community. Co-authorship of papers just documents this type of interaction even though it could be a measure of joint research and hence of the exchange of tacit knowledge. In studying cross-citation, it is interesting to see whether private sector scientists preferentially cite public sector researchers and vice versa and identify research communities with a low level of information asymmetry.

A factor behind the success of technology transfer between university and industry is the organizations' degree of openness that is measured by the number of external channels of information used to innovate. If the degree of openness is high for both, university and industry have a higher probability of considering the knowledge produced internally/externally as important for their activities. The concept of openness should be considered as the set of activities carried out to gather/reveal knowledge voluntarily to the outside world. The level of openness of an organization is related to the presence of the so-called gatekeepers, whose role is to create a common language between the actors-internal and external-to improve "connectedness" and hence knowledge sharing (Schmidt 2005; Fabrizio 2009). Importantly, both organizations must have an open approach and the exchange is successful if it is mutual; in contrast, asymmetric roles create a leader and a follower and this dyadic interaction undermines the results of collaboration. In the relationship between university and industry, the ability to share and to value knowledge also depends on the intuition of the individuals. Sun and Anderson (2010, p. 143) agree with the theoretical view according 
to which if individuals possess entrepreneurial intuition, they can act as receptors to the external environment, interpreting it at the group level (community of knowledge); they assert that if individuals are guided by their cognitive maps, they can interpret the same stimulus differently but if this causes dissonance and equivocal meaning, such a situation can potentially create valuable new learning if the group's interpretive process is handled effectively and is able to reconcile the diverse interpretations. Entrepreneurial intuition can lead the researcher to establish a spin-off which is a way to transfer knowledge and stimulate entrepreneurship simultaneously (Dell'Anno and Del Giudice 2002; Maggioni and Del Giudice 2011).

The exploitation of research results is influenced by the factors summarized above concomitantly with others including the level of propensity for entrepreneurship among researchers, in turn influenced by the mode of participation by the university in the new-co and by the required rates of return (royalties and/or profits), and the availability of consulting services to support the process of commercialization and/or the genesis of businesses.

Since the diversity of knowledge creates a cultural gap that is hard to fill, it depends on the willingness to create a harmony of interests to bring together the two worlds: one world which is very concrete and uses economic value as a guide, the other strongly knowledge-oriented and little or not at all accustomed to translating efforts and resources into monetary terms.

In trying to understand what may be the reasons for the poor ability of universities to ensure that the economic benefits from research are translated into innovation, it is necessary to analyze some aspects peculiar to market innovation and the behavior assumed by universities on the technology market. In most cases, the search paths by university researchers start from the need felt by the individual, or the research group, to seek an answer to the assumptions made on the basis of an extremely personal cultural background. Other times, questions and hypotheses are induced by the observation of reality, or, however, by contingent needs, or are stimulated by opportunities of the moment but often independently of the concrete use of the results; the search path is frequently determined by the interest to give an answer to those questions just in order to fill a knowledge gap.

For national systems that follow this approach, the risk for the community is that investments are guided by prestige and intellectual curiosity and not by the possible economic use of knowledge. This is also a key to understanding the differences between local realities in terms of measurable innovations (Schillaci et al. 2013).

The use of the market, however, has to cope with the high transaction costs due also to a high degree of uncertainty in the process of knowledge and innovation development. Moreover, especially when the tacit nature of knowledge prevails, the contracts for the transfer would be incomplete, resulting in possible opportunistic behavior. The market is indeed effective if knowledge can be used independently of the relationship between producer and user and also when the user assumes all risks (and expenses) to employ the knowledge acquired in a partial and/or inefficient manner. Therefore, the role of the market cannot be just mere impersonal mediation.

The role played by cultural aspects

Among the factors that must be acknowledged as important in interaction between academia and industry, we focus on a particular type of knowledge asset (Nonaka et al. 
2000; Nonaka et al. 2001), the individual or organizational culture. In Fig. 2, we provide a synopsis of the cultural factors influencing the university-industry knowledge transfer process.

Organizations with a more open culture are more easily able to establish social links with other organizations outside of them. The national culture affects A/DCAP in the relationship between science and industry, especially with regard to the exploitation of research: it facilitates or hinders the knowledge/technology transfer processes.

The cultural background of individuals that operate in organizations-university and industry-is able to determine and influence their behavior on social interactions and as a consequence the organizations' level of absorptive capacity. Indeed, national cultural values are embedded in individuals and shape behavior well before the working context. Individuals import into the organizations their cultural values through mental models that determine the kind of interaction with other members of the same and/or external organization (Dell'Anno et al. 2004).

The literature presents many contributions about the definition of national culture, but there is no common agreement on the topic. Greve et al. (2009), borrowing the proposition of Kluckhohn (1951), maintain that culture consists in patterned ways of

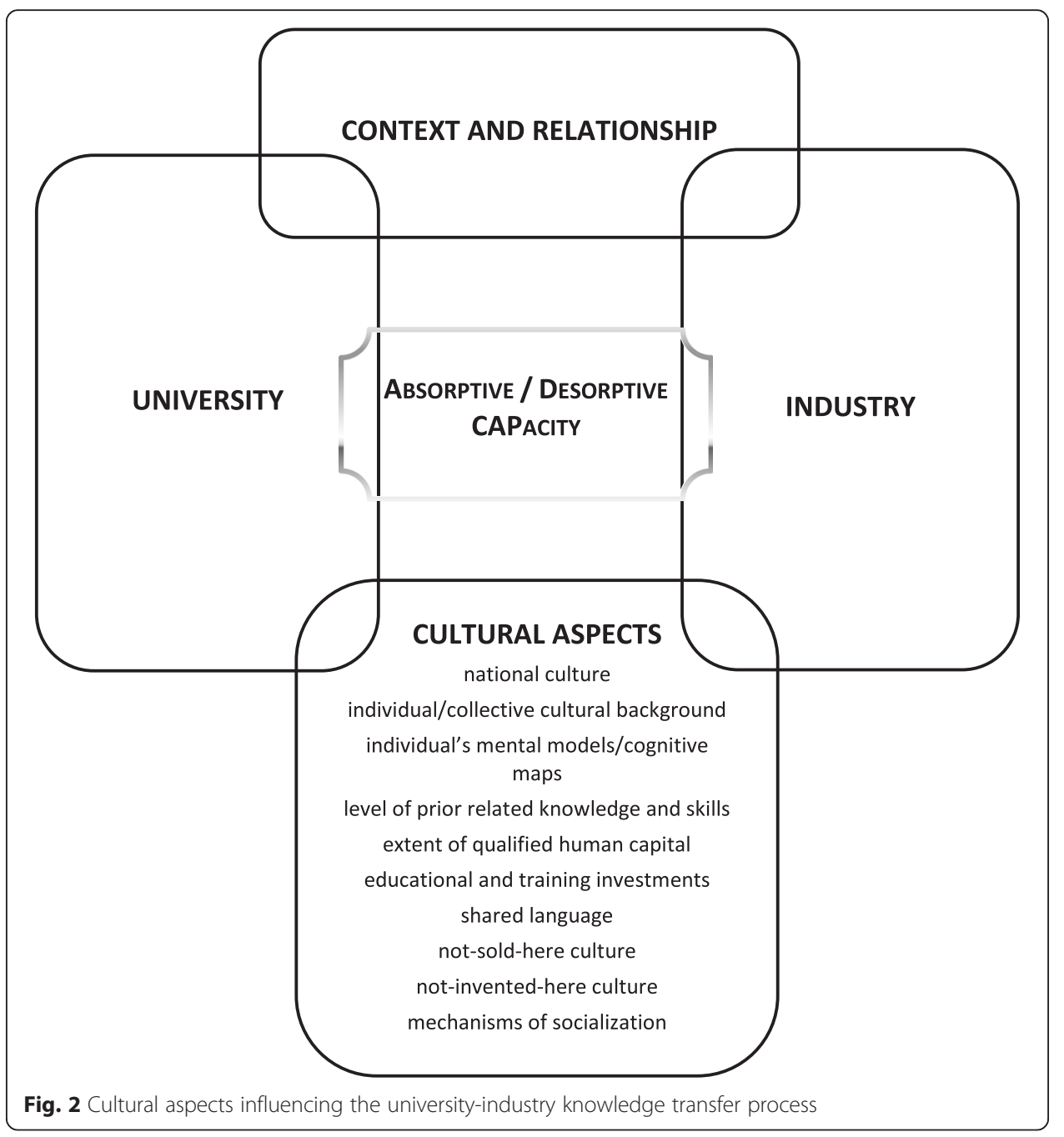


thinking, feeling, and reacting, acquired and transmitted mainly by symbols, constituting the distinctive achievements of human groups, including their embodiment in artifacts. The essential core of culture consists of traditional (i.e., historically derived and selected) ideas and especially their attached values (p. 86). Hofstede (2010) claims that culture is the collective programming of the mind distinguishing the members of one group or category of people from others; adopting a metaphor, he also called it the "software of the mind."

Further, utilizing Hofstede's cultural dimensions, Greve et al. (2009) study how far these affect the propensity to establish absorptive capacity in an organization, pinpointing three aspects. Firstly, collectivist cultures are characterized by strong ties between individuals who define themselves by belonging to a social group, such as the organization they work for, and present high degrees of informal communication and interaction, thereby matching the inherent nature of absorptive capacity. Secondly, absorptive capacity and low-power-distance cultures are compatible since there is no need to establish formal structures between superiors and subordinates; high-power-distance cultures, instead, put subordinates in an uncomfortable position as they are not used or prepared to speak up by themselves and communicate with their superiors without being asked. Lastly, long-term-oriented cultures prefer a continuous acquisition and search for new knowledge even though it can take a long time. In the meanwhile, they risk putting unimportant before important knowledge one; consequently, they present a high level of absorptive capacity, which is a strategic element.

We can therefore summarize that (i) national culture affects the A/DCAP in the relationship between university and industry, most of all in the exploitation of research; (ii) in turn, the ACAP influences knowledge and technology transfer; (iii) the broader concept of culture may include the "shared vision and systems" that promote mutual understanding and provide a crucial bonding mechanism that helps different actors to integrate knowledge (van Wijk et al. 2008, p. 835); and (iv) similarities in organizational structures contribute to organizational knowledge transfer.

The desorptive capacity of the transferor is usually manifested in the ability to release knowledge and technology; this process is then facilitated by the ability of renewal intrinsic in the system under which the new knowledge pushes out previous knowledge and/or technology. Just as for the source, prior knowledge gives way to new knowledge, for the recipient, prior knowledge facilitates the incoming of new knowledge, recognizing the potential value of external knowledge sources. Moreover, we should agree with two hypotheses: firstly, the ability of the transferor and recipient to absorb new external knowledge depends on their level of prior related knowledge and skills. Secondly, the extent of qualified human capital employed builds the organizational culture, including the ability to establish external linkages. Therefore, we should stress that education and training investments contribute to improve the stock of knowledge and then the absorptive capacity. Indeed, internal training intensifies interaction among individuals or group, amplifies existing knowledge, and may convert it into new types of knowledge (Schmidt 2009, p. 256).

A relevant variable is represented by the members of an organization, individuals who express the level of prior existing knowledge including basic skills, a shared language, and knowledge of the scientific or technological developments in a given field. The prior existing knowledge forms the humus in which absorptive capacity develops, 
namely the ability to recognize the value of new information, assimilate it, and apply it to commercial ends.

Large firms have cooperative agreements with universities more frequently than small ones because the risk of negative spillover is not a very major concern for these relationships, especially if the arrangement serves to share control costs of innovation. That said, firm size usually relates to the qualified profile of human resources that can cooperate to implement projects on innovation and also to the amount of R\&D investments and capacity. However, in many scientific technologies, firm size is not a good proxy to measure the level of absorptive capacity as it is for start-ups that have a higher probability of benefiting from academic research.

An important driver of desorptive capacity is the deep-rooted culture in universities on the approach to research. A "not-sold-here" culture, which refers to negative attitudes to outward technology transfer, is influenced by excess of empathy and jealousy that envelops the process of research and technological development. A source-individual or group - could be averse to knowledge sharing because it could lose the privilege/superiority connected to the ownership of know-how.

Knowledge relies on communication mechanisms and routines. Routines are not sufficient to support the technology transfer between industry and academia but are able to support or to impede successful transfer processes. On this point, Vega-Jurado et al. (2008, p. 397) asserts that knowledge from universities, public research institutes, and technology institutes is not immediately applicable and, as a consequence, a firm needs to develop competences that will allow it to access and exploit it efficiently. In these cases, the absorptive capacity depends on R\&D efforts but it is also important to formalize procedures and instruments in order to favor communication with other organizations that use a different language and have a diverse culture. The mechanism of socialization is useful to integrate the actors supporting the transformation and exploitation of knowledge, above all for tacit knowledge.

Firms interacting with universities in the field of $R \& D$ for innovation have many benefits. Bishop et al. (2011) consider the learning processes associated with absorptive capacity influenced by this relationship and suggest that such interactions enhance multiple types of learning capabilities along a continuum from the more explorative to the more exploitative.

The uncertainty inherent and irreducible components of knowledge, its sources and how they interact with each other, is identified as knowledge ambiguity. This results from the simultaneous effects of tacitness, complexity, and specificity of the knowledge base with respect to the possibility that they may be transferred; as a result, knowledge ambiguity is considered a predictor-in an inverse relationship-of the potential for transfer of organizational knowledge. If knowledge ambiguity is high, knowledge itself is difficult to interpret, assimilate, and apply to commercial ends. Organizations can intentionally achieve the desired level of knowledge ambiguity to prevent spillover effects and create barriers to knowledge transfer; organizations like universities and public research institutes create a high level of ambiguity unintentionally as a result of their cultural approach to research.

\section{Results and discussion}

The process of technology transfer between university and industry, considered as a sub-system of knowledge transfer, can be interpreted from many points of view. The 
transferability of knowledge is linked to the degree of adherence to the context in which it was generated: it can be sticky and difficult to transfer or slippery, even if it involves the marginal costs of dissemination and replication (Brown and Duguid 1998). Szulanski (1996) suggests that the origin of the stickiness depends on the lack of absorptive capacity of the recipient, the causal ambiguity (recipient's depth of knowledge), and an arduous relationship between the source and the recipient.

The process in question observed in a relational and activity context is influenced by three dimensions: the university's features and industry's features that interact through common technical features and relational aspects; relational and activity features are, however, common but case-specific.

The interaction between university and industry in the field of knowledge transfer could also be read using the Stokes model (Stokes 1997) which ranks scientific research by its degree of attention to the use and the focus on basic research. The greater the degree of attention to the use of research the greater the interest in the industry, as the most likely next commercial exploitation; on the contrary, when the focus on the knowledge base is high, the possible output of the search process may be independent of practical applications. The problem of the interaction between academia and industry arises especially in the first case because market rules prevail.

The market as a vehicle for transferring the results of knowledge generally creates high transaction costs, due to a high degree of uncertainty on the development of knowledge and innovation processes. Furthermore, especially in cases where tacit knowledge is prevalent, the contracts for the transfer would be incomplete, thus favoring opportunistic behavior from the counterparts. The market, in fact, is real if knowledge can be used without having to establish any relationship between the producer and the user or when the user bears the risk (and its costs) to use the acquired knowledge in a partial way. Therefore, it is confirmed that the role of the market cannot be just a mere impersonal mediation.

The nature of the technology transfer process is by its very nature problematic because it is subjected to a reification and often involves some simplifications. Technology, as a set of information, is based on a relationship of confidentiality between the parties involved in the transfer. At this stage of the transaction, many factors play a key role: the degree of trust between the parties, the stage in which that particular technology is located, and the level of protection.

In light of this, in order to sketch the outline of a model that optimizes the transfer of technology from universities in A/DCAP logic, you need to identify the system of vectors of knowledge transfer from university to industry. University-industry knowledge transfers occur through a large number of formal and informal and two-way channels (Fig. 3). Publications, conferences, and informal exchanges among scientists are considered as informal channels; formal channels include hiring students and researchers from universities and PROs, sharing equipment and instrumentation, contracting technology services, research collaboration, academic/university spin-offs, patents, and licensing (Dell'Anno 2010).

Importantly, exchanges take place in two directions, from university to industry and vice versa. In fact, industry's research path complements and often guides basic research, just as availability of equipment boosts research with new and powerful 


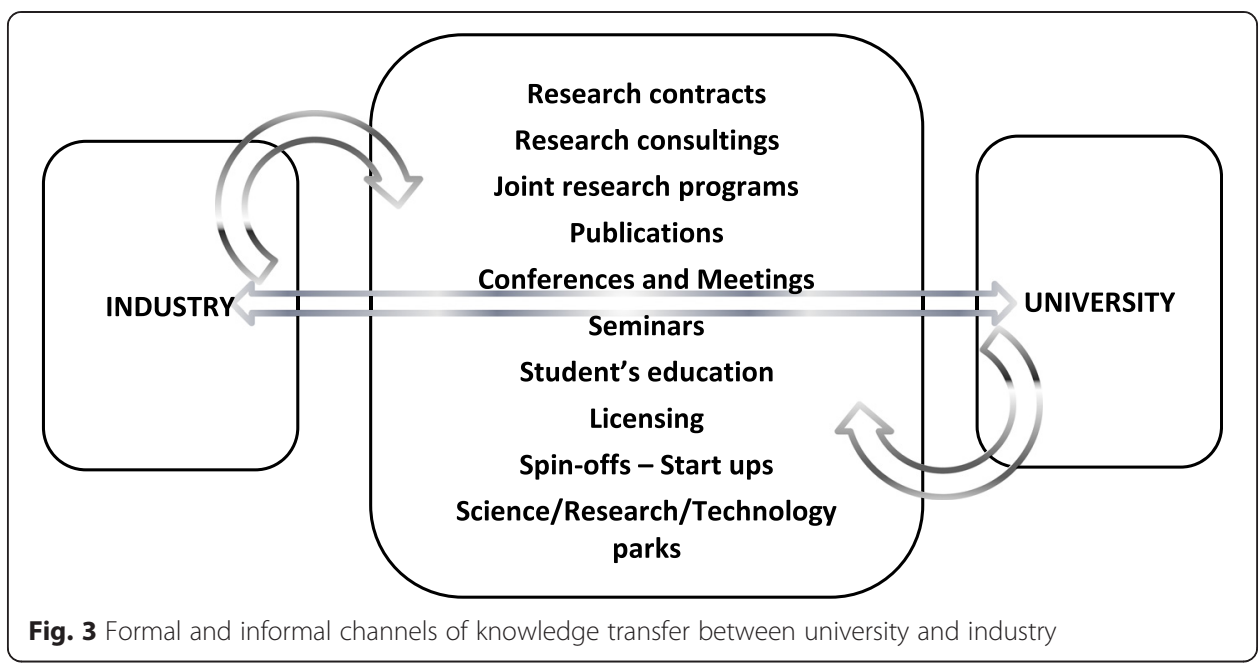

instruments. As already mentioned above, this two-way channel is underappreciated by metrics as being predominantly informal.

The difficulty of combining the interests of both the worlds of science and industry can also be interpreted by using the model proposed as the Valley of Death (Markham et al. 2002), which identifies a gap between the discovery of an idea, the subject of research funded by public resources, and efforts to market its results with private capital. The Valley of Death coincides with the phase of the innovation process immediately following that of basic research and before commercial exploitation. If public funds are almost exclusively dedicated to basic research without taking into due consideration the financing of the subsequent phases, the depth of the "valley" could be such as to stop the innovation process because (a) the potential created could be greater than the capacity of exploitation/absorption (technical and/or commercial) by the market or (b) of little technical/commercial interest for the private sector, as a direct consequence of the information asymmetry generated by the failure to balance the interests and abilities of the actors. After all, one generally prefers to invest in projects that are at an advanced stage of the innovation process, as close as possible to commercial exploitation.

Moreover, the stage immediately prior to the start of production is also the time when there is the greatest chance of spillovers, hence with all the-negative-consequences that might ensue for those who are engaged in the process without being certain to be able to exploit such production exclusively. Obviously, the occurrence of this situation has a very negative impact on the returns of public research and hence on the economic and social development of the country.

To answer our research question by proposing a model able to optimize the success of the university-industry technology transfer process, we put forward the vision of a university ideally seen like a hub, a crossroad of cultures, made of tacit and explicit knowledge, technology, and innovation, a link between training and local development, an institution that assumes the role of local development agent by facilitating the creation of knowledge and skills as well as economic value. This highlights the need for the scientific community to be supported by financial resources, both private and public, throughout the process of research and exploitation of results. Since it is natural that research uses resources with a degree of risk, it becomes necessary 
that the technology developed can return the value used in the economic system, as only in this way can the process be virtuous. Otherwise, it would create a deficit between "energy" used and obtained.

An ideal context sees the presence of innovation networks and knowledge clusters (Carayannis and Formica 2006; Dell'Anno 2008, 2010) in which knowledge is diffused within the network. Knowledge feeds on differences whose sustainability over time is proportional to the amplitude of the network, measured in terms of potential uses and units that are part of it. Individuals aggregate because of the common desire to access experience, to share ideas, and to learn from each other. Research networks and socialization ensure that knowledge clusters will increase their focus on the ways in which people manage themselves and their relationships with others, favoring the socalled soft skills (Nicotra et al. 2014). Within knowledge clusters, knowledge sharing occurs horizontally through communities of practice, and this condition fuels the development process and sedimentation of the business culture in the research environment, fostering new initiatives geared toward development and growth. In this kind of ideal system, the variables that affect the A/DCAP should be managed in a public-private partnership that will create the right conditions to foster fruitful collaboration between academia and industry in order to improve knowledge and develop technologies.

We believe that for the near future, in those countries in which university-industry relationships on technology transfer have been unsuccessful, the real challenge for academia in order to play a key role in economic systems is to improve four skills: (i) identify research programs involving industry's interest in avoiding valley of death situations, (ii) detect innovation opportunities, (iii) imagine what needs to be transferred, and (iv) enhance the propensity of academia to transfer technology. The transfer of technology from the university through the spillover effect can only occur in the presence of an ACAP on the part of firms and an adequate level of DCAP from the university. Otherwise, for universities and public laboratories, to invest in basic research is essential and consistent with the mission, even if the probability of having a spillover effect is very high, because this kind of investment creates a capacity to assimilate and to transfer/exploit new knowledge. It is therefore necessary to fine-tune and render consistent the ACAP and DCAP of the actors involved. Indeed, even if it is in the public domain, knowledge is not necessarily absorbed and exploited because an action is required by the researchers to do that.

Tacit and embedded knowledge are elicited by personal experience. Therefore, the challenge of the transfer process of the future knowledge economy will be to evolve the mind-sets of the actors, by creating strong cultural relatedness. Universities that formerly performed many innovations and created technological spillovers should be more desorptive-oriented than others (Arbussà and Coenders 2007), while firms that have some kind of ability to evaluate information (scientific capabilities) and hence the ability to utilize it (technological capabilities) consequently possess highly absorptive capacity and the probability to innovate (Arora and Gambardella 1994). The interaction between universities and firms may then contribute to fill the gap between explorative and exploitative learning capabilities, preventing the valley of death situation.

By improving the understanding of phenomena, academics could enhance awareness of exploitation of research and business opportunities. In this regard, the capacity to effectively improve "applied research" is strictly related to the capacity of universities to generate extra returns from cooperation with business organizations. This confirms the 
importance of mutual and non-exclusive cooperation in which universities assume an absorptive pro-active approach for creating knowledge. Close interaction based on labor mobility and recruitment of skilled graduates and training improve the reciprocal capacity to interpret and transmit knowledge between organizations (Bishop et al. 2011). Ability, motivation, and opportunity are important factors that explain the success of this interaction process. Academics, managers, and policymakers should invest every possible effort in promoting the creation of structures useful for interacting with each other in order to decrease the cultural differences and increase propensity to the exchange of knowledge and technology. In our opinion, the goal for the near future is to move toward a knowledge system in which science push and technology pull, on one side, and absorptive and desorptive capacity, on the other, will be the pivotal elements of a successful formula to sustain economic and social development.

Management studies usually consider inter-organizational aspects of absorptive capacity focusing on a dual process of mutual interaction between two or more businesses, but they rarely investigate these relations between two organizations, independently of their scope and/or mission. Our intent was thus not merely to review all the research trajectories related to ACAP; our observation mainly focused on studies that consider ACAP and DCAP as critical resources in knowledge transfer processes between university and industry. In this way, the link with universities creates the preconditions for industry to generate a network of complementarity in which other stakeholders are involved such as regulators, suppliers, customers, and academics. The originality of our contribution lay precisely in adopting this approach.

The issues covered in this paper appear to suggest that the frequency of collaborative ties on industry's side may be directly related to the structure of local capitalism. An industry with a high share of small businesses is probably more focused on financing incremental innovations rather than science-based research projects where the link with business is much more blurred.

On the academic side, instead, we showed that the national culture affects the A/ DCAP in the relationship with industry, especially with respect to the exploitation of research. In turn, ACAP influences knowledge and technology transfer, and similarities in organizational structures contribute to organizational knowledge transfer which would stimulate cooperation with business organizations.

\section{Conclusions}

The thoughts presented in this work aim to stimulate researchers to pursue, in future studies, further details about the relationship between absorptive and desorptive capacity in mutually interacting knowledge clusters. Certainly, other works in this field of research are needed to test empirically the importance of this topic. More importantly, the analysis should be extended by proposing cross-time or cross-cultural inquiries among different countries. Furthermore, it will be important to assess the efficiency of such cooperation by evaluating the impact on innovativeness as well as on performance and growth. Studies focusing on specific industries or university-industry relations would undoubtedly enrich the literature on the topic. In a knowledge-network economy, shedding light on A/DCAP could be interesting both for scholars and for practitioners to better assess which capacities and capabilities firms need to manage from inside and which, instead, they should take to the market, considering the transferor role of universities in the knowledge transfer process. 


\section{Competing interests}

The authors declare that they have no competing interests.

\section{Authors' contributions}

DDA authored the "Background," the "Methods," and the "Model proposal" sections, making relevant contributions to the conception of the article. MDG authored the "Literature review" and the "Results and discussion" sections, revising critically the article as well. The "Conclusions" has been jointly devised by the authors. Both authors read and approved the final manuscript.

\section{Author details}

${ }^{1}$ Department of Economics, Second University of Naples, Capua, Italy. ${ }^{2}$ University of Rome "Link Campus", Rome, Italy.

\section{Received: 27 October 2015 Accepted: 19 November 2015}

\section{Published online: 02 December 2015}

\section{References}

Adler, J. H. (1965). Absorptive capacity: the concept and its determinants. Brookings Staff Paper, Washington, D. C. Arbussà, A., \& Coenders, G. (2007). Innovation activities, use of appropriation instruments and absorptive capacity: evidence from Spanish firms. Research Policy, 36, 1545-1558.

Arrow, KJ. (1985). The economics of agency. In J. W. Pratt \& R. J. Zeckhauser (Eds.), Principals and agents: The structure of business (pp. 37-51). Harvard Business School Press, Boston.

Arora, A., \& Gambardella, A. (1994). Evaluating technological information and utilizing it. Journal of Economic Behavior and Organization, 24, 91-114.

Barney, J. (1991). Firm resources and sustained competitive advantage. Journal of Management, 17(1), 99-120.

Bishop, K., D'Este, P., \& Neely, A. (2011). Gaining from interactions with universities: multiple methods for nurturing absorptive capacity. Research Policy, 40, 30-40.

Bowen, H.R. (1980). The Costs of Higher Education: How much do colleges and universities spend per student and how much should they spend?, Jossey-Bass Publishers, Washington.

Branscomb, L. M., Kodama, F., Florida, R. (Eds.). (1999). Industrializing knowledge: University-industry linkages in Japan and the United States. London, The MIT Press.

Brown, J. S., \& Duguid, P. (1998). Organizing knowledge. California Management Review, 40(3), 90-111.

Carayannis, E. G., \& Formica, P. (2006). Intellectual venture capitalists: an emerging breed of knowledge entrepreneurs. Industry and Higher Education, June, 141-156.

Carayannis, E. G., Barth, T. D., \& Campbell, D. F. J. (2012). The Quintuple Helix innovation model: global warming as a challenge and driver for innovation. Journal of Innovation and Entrepreneurship, 1, 2. doi:10.1186/2192-5372-1-2.

Carlsson, S. A. (2005). Enabling and enhancing potential absorptive capacity through the use of ICT, Lund on Informatics.

Cassiman, B., \& Veugelers R. (2000). External technology sources: embodied or disembodied technology acquisition, EconPapers. https://lirias.kuleuven.be/bitstream/123456789/102903/1/OR_0004.pdf. Accessed 25 November 2014.

Cockburn, I. M., \& Henderson, R. M. (1998). Absorptive capacity, coauthoring behavior, and the organization of research in drug discovery. The Journal of Industrial Economics 0022-1821, XLVI(2), 157-182.

Cohen, W. M., \& Levinthal, D. A. (1990). Absorptive capacity: a new perspective on learning and innovation. Administrative Science Quarterly, 35, 128-152.

Davenport, T. H., \& Prusak, L. (2000). Il sapere al lavoro. Milan: ETAS.

David, P. \& Foray D. (1995). Accessing and expanding the science and technology knowledge-base, STI Review, no 16, Paris, OECD.

Del Giudice, M., Della Peruta, M. R., \& Maggioni, V. (2013). Collective knowledge and organizational routines within academic communities of practice: an empirical research on science-entrepreneurs. Journal of the Knowledge Economy, 4(3), 260-27.

Dell'Anno, D., \& Del Giudice, M. (2002). The spin off model: a simultaneous way to knowledge transfer and entrepreneurship stimulation, Proceedings "7th World Congress for Total Quality Management", Sinergie-Cueim.

Dell'Anno, D., Van der Sijde, P., \& Del Giudice, M. (2004). A script-based approach to spin off: some first issues on innovative pathways of knowledge transfer and academic knowledge's reproducibility. 12th HTSF Conference, 25th May. Twente: Twente University Press.

Dell'Anno, D. (2008). The knowledge-based entrepreneurship in a boundless research system. Industry and Higher Education, 22, 387-393.

Dell'Anno, D. (2010). La conoscenza dall'università allimpresa. Processi di trasferimento tecnologico e sviluppo locale. Roma: Carocci editore.

Del Giudice, M., Carayannis, E. G., \& Della Peruta, M. R. (2012). Culture and cooperative strategies: knowledge management perspectives. Cross-cultural knowledge management (pp. 49-62). New York: Springer.

Dine Rabeh, H.A. (2013). Firm resources' entanglement determines its absorptive capacity: a review towards a new reconceptualization. Cahiers Du Lab.Rii, №270 Juin.

Eisenhardt, K. M (1989). Agency theory: An assessment and review. Academy of Management Review, 14, 57-74.

Etzkowitz, H. (1998). The norms of entrepreneurial science: cognitive effects of the new university-industry linkages. Research Policy, 27, 823-833.

Etzkowitz, H. \& Leydesdorff, L. (2000). The dynamics of innovation: from National Systems and 'Mode 2' to a Triple Helix of university-industry-government relations. Research Policy, 29(2), 109-123.

Fabrizio, K. R. (2009). Absorptive capacity and the search for innovation. Research Policy, 38, 255-267.

Feller I. (1990). Universities as engines of R\&D-based economic growth: they think they can. Research Policy, 19, 335-348,

Flatten, T. C., Greve, G. I., \& Brettel, M. (2011). Absorptive capacity and firm performance in SMEs: the mediating influence of strategic alliances. European Management Review, 8, 137-152.

Freeman, C. (1991). Networks of innovators: a synthesis of research issues. Research Policy, 20, 499-514. 
Greve, G., Engelen, A., \& Brettel, M. (2009). An integrative view on absorptive capacity and national culture. International Journal of Business Studies, 17(1), 19-43.

Hofstede, G. (2010). The GLOBE debate: back to relevance. Journal of International Business Studies, 41(8), 1339-46.

Kedia, B. L., \& Bhagat, R. S. (1988). Cultural constraints on transfer of technology across nations: implications for research in international and comparative management. Academy of Management Review, 13(4), 559-571.

Kluckhohn, C. (1951). Values and Value Orientations in the Theory of Action: An Exploration in Definition and Classification. In Toward a General Theory of Action, eds. Talcott Parsons and Edward Shils, Cambridge: Harvard University Press, 388-433.

Lane, P. J., Koka, B. R., \& Pathak, S. (2006). The reification of absorptive capacity: a critical review and rejuvenation of the construct. Academy of Management Review, 31(4), 833-863.

Lane, P. J., \& Lubatkin, M. (1998). Relative absorptive capacity and interorganizational learning. Strategic Management Journal, 19, 461-477.

Le Masson, P., Cogez, P., Felk, Y., \& Weil, B. (2012). Revisiting absorptive capacity with a design perspective. International Journal of Knowledge Management Studies, 5, 10-44.

Lundvall, B.A. (1992). National systems of innovation: towards a theory of innovation and interactive learning, Pinter, London.

Maggioni, V., \& Del Giudice, M. (2011). Relazioni sistemiche tra imprenditorialità interna e gemmazione d'impresa: una ricerca empirica sulla natura cognitiva delle nuove imprese. Sinergie, 71, 171-197.

Mansfield, E. Academic Research and Industrial Innovation (1991). Research Policy, 20(1), 1-12.

Markham, S.K. (2002). Moving technologies from lab to market. Research Technology Management, 45, $31-42$.

Minbaeva, D., Pedersen, T., Bjorkman, I., Fey, C. F., \& Park, H. J. (2003). MNC knowledge transfer, subsidiary absorptive capacity, and HRM. Journal of International Business Studies, 34, 586-599.

Murovec, N., \& Prodan, I. (2009). Absorptive capacity, its determinants and influence on innovation output: crosscultural validation of the structural model. Technovation, 29, 859-872.

Nelson, R.R. (1993). National innovation systems: a comparative analysis. Oxford University Press, Inc.

Nicotra, M., Romano, M., \& Del Giudice, M. (2014). The evolution dynamic of a cluster knowledge network: the role of firms' absorptive capacity. Journal of the Knowledge Economy, 5(2), 240-264.

Nonaka, I., \& Konno, N. (1998). The concept of "Ba": building a foundation for knowledge creation. California Management Review, 40(3), 40-54.

Nonaka, I., \& Takeuchi, H. (1995). The knowledge creating company. Oxford: Oxford University Press.

Nonaka, I., Toyama, R., \& Byosieère, P. (2001). A theory of organizational knowledge creation: understanding the dynamic process of creating knowledge. In M. Dierkes, A. Berthoin Antal, J. Child, \& I. Nonaka (Eds.), Handbook of organizational learning \& knowledge. Oxford: Oxford University Press.

Nonaka, I., Toyama, R., \& Konno, N. (2000). Seci, ba and leadership: a unified model of dynamic knowledge creation. Long Range Planning, 33, 5-34.

OECD. (2013). OECD Science, Technology and Industry Scoreboard 2013, OECD Publishing. doi:10.1787/sti_scoreboard-2013-en.

Oliver, C. (1991). Strategic Responses to Institutional Processes. The Academy of Management Review, 16(1), 145-179.

Patel, P. \& Pavitt, K. (1994). National Innovation Systems: Why they are Important, and how they might be Measured and Compared. Economics of Innovation and New Technology, 3, 77-95.

Paulsen, J. M., \& Hjertø, K. B. (2010). Organizational knowledge transfer: introducing a multi-level perspective, AoM Montreal, 9th August.

Penrose, E. T. (1959). The theory of growth of the firm. New York: Blackwell-Oxford-John Wiley and Sons.

Penrose, E.T. (1995). The Theory of the Growth of the Firm. Oxford University Press.

Pfeffer, J. \& Salancik, G. R. (1978). The External Control of Organizations: A Resource Dependence Perspective, Harper \& Row, New York.

Robertson, P. L., Casali, G. L., \& Jacobson, D. (2012). Managing open incremental process innovation: absorptive capacity and distributed learning. Research Policy, 41, 822-832.

Rogers, M. (2004). Absorptive capability and economic growth: how do countries catch-up? Cambridge Journal of Economics, 28, 577-596.

Rosenberg, N. \& Nelson R. (1994). American universities and technical advance in industry. Research Policy, 23(3), 323-348.

Rothwell, R. (1992). Successful Industrial Innovation: Critical Success Factors for the 1990's. R\&D Management, 22/3, 221-239.

Rothwell, R., \& Dodgson, M. (1994). Innovation and size of firm. In M. Dodgson \& R. Rothwell (Eds.), The Handbook of Industrial Innovation. Aldershot: Edward Elgar.

Samuelson, P. (1999). Challenges for the World Intellectual Property Organization and the Trade-related Aspects of Intellectual Property Rights Council in Regulating Intellectual Property Rights in the Information Age, E.I.P.R. 11, 578-591.

Schillaci, C.E., Romano M., Nicotra M. (2013). Territory's Absorptive Capacity. Entrepreneurship Research Journal, 3(1), 109-126. doi:10.1515/ERJ-2012-0001.

Schmidt, S. (2009). Measuring absorptive capacity. Proceedings of the International Conference on Intellectual Capital, Knowledge Management \&Organizational Learning.

Schmidt, T. (2005). Absorptive capacity—one size fits all? A firm-level analysis of absorptive capacity for different kinds of knowledge, ZEW - Centre for European Economic Research Discussion, Paper No. 05-72.

Schofield, T. (2013). Critical success factors for knowledge transfer collaborations between university and industry. Journal of Research Administration, 44, 2. Fall.

Segarra-Blasco, A., \& Arauzo-Carod, J. M. (2008). Sources of innovation and industry-university interaction: evidence from Spanish firms. Research Policy, 37, 1283-1295.

Stokes, D. E. (1997). Pasteur's quadrant-basic science and technological innovation. Washington: Brookings Institutions Press.

Sun, P. Y. T., \& Anderson, M. H. (2010). An examination of the relationship between absorptive capacity and organizational learning, and a proposed integration. International Journal of Management Reviews. doi:10.1111/j.1468-2370.2008.00256.x. 
Szulanski, G. (1996). Exploring internal stickiness: impediments to the transfer of best practice within the firm. Strategic Management Journal, 17, 27-43.

Teece, D. J. (1988). Capturing value from knowledge assets: the new economy, markets for know-how, and intangible assets. California Management Review, 40(3), 55-79.

Todorova, G., \& Durisin, B. (2007). Absorptive capacity: valuing a reconceptualization. Academy of Management Review, 32(3), 774-786.

van Wijk, R., Jansen, J. J. P., \& Lyles, M. A. (2008). Inter- and intra-organizational knowledge transfer: a meta-analytic review and assessment of its antecedents and consequences. Journal of Management Studies, 45(4), 830-853.

Vega-Jurado, J., Gutierrez-Gracia, A., \& Fernandez de Lucio, I. (2008). An analytical model of absorptive capacity, INGENIO, WP 2/2008.

Veugelers, R., \& Cassiman, B. (2005). R\&D cooperation between firms and universities. Some empirical evidence from Belgian manufacturing. International Journal of Industrial Organization, 23(5-6), 355-379.

Volberda, H. W., Foss, N. J., \& Lyles, M. A. (2010). Absorbing the concept of absorptive capacity: how to realize its potential in the organization field. Organization Science, 21, 931-951.

Williamson, O. (1985). The economic institutions of capitalism. Free Press, New York, NY.

Zahra, S. A., \& George, G. (2002). Absorptive capacity: a review, reconceptualization and extension. Academy of Management Review, 27(2), 185-203.

\section{Submit your manuscript to a SpringerOpen ${ }^{\circ}$ journal and benefit from:}

- Convenient online submission

- Rigorous peer review

- Immediate publication on acceptance

- Open access: articles freely available online

- High visibility within the field

- Retaining the copyright to your article

Submit your next manuscript at $\boldsymbol{~ s p r i n g e r o p e n . c o m ~}$ 